\title{
Risk factors for delayed and non-union following transfibular ankle arthrodesis
}

\author{
Hyeon Soo Kim, Sung Jin Shin*, Jin Woo Kim
}

\begin{abstract}
Department of Orthopaedic Surgery, Samsung Changwon Hospital, Sungkyunkwan University School of Medicine, Changwon, Korea
\end{abstract}

Received: 21 January 2021

Revised: 09 February 2021

Accepted: 10 February 2021

*Correspondence:

Dr. Sung Jin Shin,

E-mail: orthoshin@gmail.com

Copyright: (c) the author(s), publisher and licensee Medip Academy. This is an open-access article distributed under the terms of the Creative Commons Attribution Non-Commercial License, which permits unrestricted non-commercial use, distribution, and reproduction in any medium, provided the original work is properly cited.

\begin{abstract}
Background: This study was to identify risk factors associated with delayed union and non-union in patients who underwent transfibular ankle arthrodesis.

Methods: This study included 43 patients who underwent ankle arthrodesis using transfibular approach between January 2012 and September 2018 and were followed up for more than 12 months. The patients were divided into two groups according to delayed union or non-union. Group A included patients who had delayed union or non-union and Group B included patients without these complications. Variables that could contribute to non-union including etiologies, age, chronic renal failure, hypertension, diabetes, smoking, pre-operative talus bone quality, pre-operative angulation of the talus and fixation methods were evaluated.

Results: The mean time to bone union was 12.7 \pm 7.25 weeks. Group A included 12 patients with 5 cases of non-union and 7 cases of delayed union and group B included 31 patients. Infection of the ankle joint $(\mathrm{OR}, 1.73 ; \mathrm{p}=0.041)$ was risk factor for non-union and delayed union on the basis of multivariate analysis.

Conclusions: We concluded that infection of the ankle joint is the most significant risk factor for delayed union and nonunion in our study. Careful attention should be paid preoperatively, intraoperatively and postoperatively to patients who have this risk factor to obtain a satisfactory surgical outcome.
\end{abstract}

Keywords: Delayed union, Non-union, Transfibular ankle arthrodesis

\section{INTRODUCTION}

Many different types of ankle arthrodesis such as open ankle arthrodesis, arthroscopic arthrodesis, mini-open arthrodesis and transfibular ankle arthrodesis have been reported to date. ${ }^{1}$ It has been reported that the average union rate following ankle arthrodesis ranged from $89 \%$ to $94 \%$ regardless the type of surgical procedures. ${ }^{2,3}$

Among these treatment methods, transfibular ankle arthrodesis was first introduced by Horwitz and has been modified in its techniques. ${ }^{4}$ This method makes it easier to identify bony deformities or soft tissue lesions around the ankle joint during the operation and provides with ankle joint stability using autologous a fibular graft. ${ }^{1,2,5,6}$

The purpose of this study is to identify the risk factors for delayed union or non-union following transfibular ankle arthrodesis.

\section{METHODS}

This study included 43 patients who underwent ankle arthrodesis using a transfibular approach between January 2012 and September 2019 and were followed up for more than 12 months. 
All patients underwent modified transfibular ankle arthrodesis which was based on Mann's technique.? Autologous cancellous bone grafting or strut graft from the resected fibular was used in all cases.

The patients were divided into two groups according to delayed union or non-union. Group A included patients who had delayed union or non-union and Group B included patients without these complications.

Radiographic union was defined when bony trabeculae bridging was seen in 3 of the 4 cortices on the anteroposterior and lateral radiographs of the ankle. ${ }^{1}$ Delayed union was defined as union taking longer than 6 months and non-union was defined as no evidence of union at 12 months after surgery. ${ }^{8}$

The t-test was used in continuous variables and Fisher's Exact test and chi-square test were used to determine the differences in outcomes between two groups. Univariate and Multivariate logistic regression analysis was used to evaluate the effect of individual risks on delayed union and non-union. $\mathrm{P}<0.05$ were considered to indicate statistical significance. Stata 15.1 (Stata Corporation, College Station, TX, USA) was used in all analyses.

\section{RESULTS}

The average age of the patients was $62.9 \pm 13.62$ years and the mean follow-up period was 16.7 months. Twenty three patients were men and twenty were women. Diagnoses were osteoarthritis $(n=20)$, traumatic arthritis $(n=6)$, septic arthritis or osteomyelitis $(n=8)$, talar necrosis $(n=2)$, ankle deformity $(n=3)$, Charcot joint $(n=2)$ and previous ankle arthrodesis failure $(\mathrm{n}=2)$.

The mean time to bone union was $12.7 \pm 7.25$ weeks. As for the fixation methods, the use of multiple screws fixation with bony staples was used in 34 cases, intramedullary nailing in 3 cases and plate fixation was 6 cases. Group A included 12 patients with 5 cases of non-union and 7 cases of delayed union and group B included 31 patients.

Variables that could contribute to non-union including etiologies, age, body mass index, chronic renal failure, hypertension, diabetes, smoking, regular alcohol use, preoperative talus bone quality, pre-operative angulation of the talus and fixation methods were evaluated. ${ }^{10,11}$ (Table 1)

Regular alcohol use $(\mathrm{p}=0.024)$ was correlated with group A $(66.67 \%$ versus $29.03 \%)$ and infection of the ankle joint was more often in group $\mathrm{A}(\mathrm{p}=0.03)$. The average preoperative talar tilt was $9.25 \pm$ in group $\mathrm{A}$ and $4.95 \pm$ in group B, respectively and this was correlated with group A $(p=0.049)$. Infection of the ankle joint (OR, 1.73; $\mathrm{p}=0.041)$ were risk factors for non-union and delayed union on the basis of multivariate analysis. (Table 2)

Table 1: Patients demographics.

\begin{tabular}{|c|c|c|c|c|c|}
\hline \multicolumn{3}{|c|}{ Variables } & Group A $(n=12)$ & Group B $(n=31)$ & $P$ value \\
\hline \multicolumn{3}{|l|}{ Male } & 8 & 15 & \multirow{2}{*}{0.281} \\
\hline \multicolumn{3}{|l|}{ Female } & 4 & 16 & \\
\hline \multicolumn{3}{|l|}{ Age } & $64.25 \pm 12.34$ & $62.48 \pm 14.46$ & 0.711 \\
\hline \multirow{3}{*}{\multicolumn{2}{|c|}{ Instruments }} & IM nailing & 1 & 2 & 1.00 \\
\hline & & Plate fixation & 4 & 2 & 0.052 \\
\hline & & Screws fixation & 7 & 27 & 0.088 \\
\hline \multicolumn{3}{|c|}{ Smoking } & $4(33.33 \%)$ & $8(25.81 \%)$ & 0.711 \\
\hline \multicolumn{3}{|c|}{ Alcohol use } & $8(66.67 \%)$ & $9(29.03 \%)$ & 0.024 \\
\hline \multicolumn{3}{|c|}{ Diabetes } & 5 & 18 & 0.334 \\
\hline \multicolumn{3}{|c|}{ Hypertension } & 5 & 11 & 0.737 \\
\hline \multicolumn{3}{|c|}{ Chronic renal failure } & $1(8.33 \%)$ & $3(9.68 \%)$ & 1.000 \\
\hline \multicolumn{3}{|l|}{ Dialysis } & $1(8.33 \%)$ & $2(6.45 \%)$ & 1.000 \\
\hline \multicolumn{3}{|l|}{ BMI } & $23.45 \pm 2.82$ & $26.64 \pm 4.15$ & 0.367 \\
\hline \multirow{7}{*}{ Causes } & Ava & ular necrosis of talus & $2(16.67 \%)$ & $0(0.00 \%)$ & 0.073 \\
\hline & Cha & ot joint & $0(0.00 \%)$ & $2(6.45 \%)$ & 1.000 \\
\hline & Ost & arthritis & $4(33.33 \%)$ & $16(51.61 \%)$ & 0.327 \\
\hline & Tra & latic arthritis & $1(8.33 \%)$ & $5(16.13 \%)$ & 0.659 \\
\hline & Infe & ion(osteomyelitis) & $5(41.7 \%)$ & $3(9.6 \%)$ & 0.03 \\
\hline & Anl & deformity & $0(0.00 \%)$ & $3(9.68 \%)$ & 0.548 \\
\hline & $\begin{array}{l}\text { Pre } \\
\text { fail }\end{array}$ & us ankle arthrodesis & $0(0.00 \%)$ & $2(6.45 \%)$ & 1.000 \\
\hline \multicolumn{3}{|c|}{ Preoperative talar tilt } & $9.25 \pm 8.62$ & $4.95 \pm 5.08$ & 0.049 \\
\hline
\end{tabular}


Table 2: Significant risk factor for delayed union and non-union following transfibular ankle arthrodesis as determined by multivariate logistic regression analysis.

\begin{tabular}{|lll|}
\hline Risk factor & OR(95\% CI) & P value \\
\hline Regular alcohol use & $\begin{array}{l}4.29(0.83- \\
22.21)\end{array}$ & 0.083 \\
\hline Infection(osteomyelitis) & $\begin{array}{l}1.73(1.02- \\
7.49)\end{array}$ & 0.041 \\
\hline Preoperative talar tilt & $\begin{array}{l}1.10(1.00- \\
1.22)\end{array}$ & 0.061 \\
\hline
\end{tabular}

OR: odds ratio, $\mathrm{CI}$ : confidence interval

\section{DISCUSSION}

Numerous risks factors for non-union following ankle arthrodesis have been proposed..$^{3,7,9,10}$ Heavy smoking, construct instability, poor vascularity, early postoperative weight bearing and gaps at the arthrodesis site could be considered as the most important risk factors for non-union following foot and ankle arthrodesis. ${ }^{10}$ Thevendran et al categorized the risk factors into patient factors and surgical factors. ${ }^{9,10}$ Patient factors are both systemic factors including age, obesity, and medical condition and local factors including infection and soft tissue condition. Surgical factors include construct stability and surgeon's volume (high versus low). ${ }^{10}$ But, very little research has been reported on the surgical results of transfibular ankle arthrodesis. Thus, the purpose of this study is to identify the risk factors for non-union following transfibular ankle arthrodesis.

In this study, regular alcohol use, infection and preoperative talar tilt were significantly different between two groups. And then multivariate a logistic regression analysis was conducted to identify the risk factors among those variables and regular alcohol use and infection were identified as independent risk factors.

With regard to preoperative talar tilt, the average talar tilt was $9.25 \pm$ in group A and $4.95 \pm$ in group B, respectively and these degrees were significantly different between the two groups $(\mathrm{p}=0.049)$. Preoperative talar tilt was measured from standing anterior-posterior radiographs. The degree of the talar tilt may indicate the severity of deformity and soft tissue contracture in the ankle joint. Collision between the distal tibia and talus may be the cause of the sclerotic change in the talus and distal tibia, which could have also led to worsening bone quality at the arthrodesis site and poor bone quality had a marked effect on the stability of ankle fusion. ${ }^{11}$

Our study revealed that regular alcohol use was correlated with delayed union or non-union although there is little evidence to show a direct adverse effect of alcohol use on bone healing. ${ }^{9}$ It might have indirect effect on malnutrition and organ damage and these effects might be associated with bone healing.
Infection has been a well known risk factor for non-union because of its adverse effect on bone healing. ${ }^{9}$ In our study, osteomyelitis observed in 5 cases $(41.7 \%)$ in group A might have contributed to delayed union and non-union (OR, 1.73; $\mathrm{p}=0.041)$. A typical sequelae of osteomyelitis of the talus is structural collapse, which makes it difficult to prepare the fusion site of ankle arthrodesis and needs more additional bone grafting due to bone loss. Poor bone stock may lead to inadequate screw purchase, resulting in failed ankle fusion. ${ }^{12,13}$

This report has some limitations, such as the retrospective nature of the study and the small sample size. However, the main objectives of this study were to identify risk factors associated with delayed union or non-union following transfibular ankle arthrodesis.

\section{CONCLUSION}

We concluded that infection of the ankle joint is the most significant risk factor for delayed union and nonunion in our study. Careful attention should be paid preoperatively, intraoperatively and postoperatively to patients who have these risk factors to obtain a satisfactory surgical outcome.

\section{Funding: No funding sources \\ Conflict of interest: None declared}

Ethical approval: The study was approved by the institutional ethics committee

\section{REFERENCES}

1. Kim JG, Ha DJ, Gwak HC, Kin CW, Kim JH, Lee SJ et al. Ankle Arthrodesis: A Comparison of Anterior Approach and Transfibular Approach. Clin Orthop Surg. 2018;10:368-73.

2. Lee DY, Kyung MG, Cho YJ, Hwang S, Kang HW, Lee DO. A modified transfibular technique of anke arthrodesis using partial fibular resection and onlay bone graft. PLos One. 2020;15(10):e0241141.

3. Yasui Y, Hannon CP, Seow D, Kennedy JG. Ankle arthrodesis: A systematic approach and review of the literature. World J Orthop. 2016;7:700-8.

4. Horwitz T. The use of the transfibular approach in the arthrodesis of the ankle. Am J Surg. 1942;55:550-52.

5. Sung W, Greenhagen RM, Hobizal KB, Burns PR, Wukich DK. Technical guide: transfibular ankle arthrodesis with fibular-onlay strut graft. J Foot Ankle Surg. 2010;49:566-70.

6. Lee HJ, Min WK, Kim JS, Yoon SD, Kim DH. Transfibular ankle arthrodesis using burring, curettage, multiple drilling, and fixation with two retrograde screws through a single lateral incision. J Orthop Surg (Hong Kong). 2016;24:101-5.

7. Mann RA, Van Manen JW, Wapner K, Martin J. Ankle fusion. Clin Orthop Relat Res. 1991;268:4955.

8. Quayle J, Shafafy R, Khan MA, Ghosh K, Sakellarious A, Gougoulias N. Arthroscopic versus 
open ankle arthrodesis. Foot Ankle Surg. 2018;24:137-42.

9. Thevendran G, Younger A, Pinney S. Current concepts review: risk factors for nonunions in foot and ankle arthrodesis. Foot Ankle Int. 2012;33(11):1031-40.

10. Thevendran G. Shah K, Pinney SJ, Younger AS. Perceived risks factors for nonunions following foot and ankle arthrodesis. J Orthop Surg (Hong Kong). 2017;25(1)2309499017692703.

11. Alonso-Vazquez A, Lauge-Pedersen H, Lidgren L, Talylor M. The effect of bone quality on the stability of ankle arthrodesis. A finite element study. Foot Ankle Int. 2004;25:840-50.
12. Stapleton JJ, Zgonis T. Concomitant osteomyelitis and avascular necrosis of the talus treated with talectomy and tibiocalcaneal arthrodesis. Clin Podiatr Med Surg. 2013;30:251-6.

13. Moore J, Berberian WS, Lee M. An analysis of 2 fusion methods for the treatment of osteomyelitis following fractures about the ankle. Foot Ankle Int. 2015;36:547-55.

Cite this article as: Kim HS, Shin SJ, Kim JW. Risk factors for delayed and non-union following transfibular ankle arthrodesis. Int J Res Orthop 2021;7:199-202. 